\title{
Servikal Sitolojinin Postkoital Kanamada Tanısal Önemi
}

\author{
Ayşe KONAÇ*, Abdullah Yüksel BARUT***
}

\section{$\ddot{O} \mathbf{z}$}

Amaç: $\mathrm{Bu}$ çalışmada postkoital kanama şikâyeti ile gelen hastalarda servikal sitolojinin preinvaziv veya invaziv servikal patolojilerin tespit edilmesindeki güvenilirliğini araştırmak ve aşırı kanama, anormal sitoloji durumlarındaki yönetim şeklini belirlemek amaçlanmıştır.

Yöntem: İstanbul Eğitim ve Araştırma Hastanesi’ne postkoital kanama şikâyeti ile başvuran ve servikal sitoloji ve kolposkopi yapılan 178 hasta retrospektif olarak smear sonucu normal olanlar ve smear sonucu anormal olanlar olarak 2 gruba ayrılmıştır.

Bulgular: Biyopsi sonuçları hem gruplar arasında hem de menopozda olup olmamalarına göre karşılaştırıldı. PAP smear için preinvaziv ve invaziv patoloji açısından sensitivite ve spesifisite hesaplanmıştır.

Sonuç: Postkoital kanama şikâyeti ile müracaat eden hastalarda gözle görünür bir lezyona sahip olmayan ve smear sonucu negatif olan grupta kolposkopi yapmak anlamlı değildir. Aşırı kanaması olan ya da PAP smear sonucu anormal olan ya da servikste lezyonu olan hastalarda mutlaka kolposkopik muayene ve biyopsi yapılması gerekmektedir.

Anahtar Kelimeler: Postkoital kanama, servikal sitoloji, kolposkopi.

\section{Diagnostic Importance of Cervical Cytology in Postcoital Bleeding}

\begin{abstract}
Aim: Our primary aim is to investigate the efficacy of cytology to detect preinvasive and/or invasive cervical pathologies in patients with postcoital bleeding and our secondary aim is to

\footnotetext{
Özgün Araştırma Makalesi (Original Research Article)

Geliş / Received: 19.09.2020 \& Kabul / Accepted: 25.11.2020

DOI: https://doi.org/10.38079/igusabder.797391

${ }^{*}$ Dr. Öğr. Üyesi, İstanbul Gelişim Üniversitesi, Sağllk Bilimleri Yüksekokulu, İstanbul, Türkiye, E-posta: akonac@gelisim.edu.tr ORCID https://orcid.org/o000-0002-9119-3332

${ }_{* * *}$ Dr. Öğr. Üyesi, İstanbul Gelişim Üniversitesi, Sağlık Bilimleri Yüksekokulu, İstanbul, Türkiye, E-posta: aybarut@gelisim.edu.tr ORCID https://orcid.org/0000-0002-7861-0736
} 
determine the management of postcoital bleeding with severe bleeding, abnormal cytology and normal cytology.

Methods: 178 patients who applied to Istanbul Training and Research Hospital with the complaint of postcoital bleeding and underwent cervical cytology and colposcopy were retrospectively divided into 2 groups: with normal smear (Group 1) and with abnormal smear (Group 2).

Results: Biopsy results were compared between both groups and menopausal status. Sensitivity and specificity of pap smear were calculated for preinvasive and invasive pathology.

Conclusion: In the total patient group, it was observed that the highest rate of invasive cancer was in group without smear due to severe bleeding (Group 1), and lowest rate was in group with normal cytology (Group 2). Colposcopy is unnecessary without visible lesion and with negative smear. However, colposcopic examination and biopsy are necessary for patients with bleeding during the examination or with abnormal smear results.

Keywords: Postcoital bleeding, cytology, colposcopy.

\section{Giriş}

Postkoital görülen, menstrual nedenle olmayan lekelenme veya kanamalar postkoital kanama olarak tanımlanmaktadır. Servikal kanser saptanan kadınların yaklaşık \%11'i başlangıçta postkoital kanama şikâyeti ile karşımıza çıkmaktadır ${ }^{1}$. Postkoital kanamanın sebepleri arasında: servikal, endometriyal polipler gibi benign oluşumlar; servisit, vajinit gibi infeksiyonlar; herpes, sifiliz gibi etkenlere bağlı lezyonlar; atrofi, endometriozis gibi benign durumlar; yabancı cisim, seksüel istismar gibi travmalar; vajen, endometrium, serviks kanseri gibi malign durumlar yer almaktadır². Postkoital kanama şikâyeti olan hastaların 1/3'de koitus ile ilişkili olmayan anormal uterus kanaması ve yaklaşık \%15’inde disparoni şikâyeti görülmektedir ${ }^{3}$. Postkoital kanama prevalansı ortalama \%o,7-9 dur. Bu farkın en büyük sebebini semptom tanımındaki farklılıklar oluşturmaktadır ${ }^{4}$. Postkoital kanamalı hastalar değerlendirildiğinde ise servikal preinvaziv ve invaziv lezyon prevalansı \%3-17,8 olarak gözlenmektedir 5 .

Postkoital kanama şikâyetiyle gelen hastalarda servikal sitolojinin preinvaziv veya invaziv patolojilerin saptanmasını ve aşırı kanama, anormal sitoloji ve normal sitoloji durumlarında yönetim şeklini belirlemek amaçlanmıştır. 


\section{Gereç ve Yöntem}

Bu çalışma 2008 ile 2010 tarihleri arasında İstanbul Eğitim ve Araştırma Hastanesi Kadın Doğum Kliniğinde, 19-69 yaş aralığında, postkoital kanama şikayeti ile gelen ve kolposkopi ve Pap smear yapılan hastaların patolojik incelemesinin retrospektif olarak değerlendirilmesi ile yapılmıştır. Bu çalışma için 11.09.2020 tarih ve 2020-24 sayılı Etik Kurul Onayı alınmıştır.

Daha önce histerektomi operasyonu olan hastalar, gebeler, daha önceden servikal preinvaziv/invaziv lezyon tanısı almış olan hastalar ya da çalışmayı kabul etmeyen hastalar bu çalışmanın dışında tutulmuştur.

Postkoital kanama: İlişki sırasında görülen, menstruasyon ile ilişkili olmayan, lekelenme veya kanama olarak tarif edilmektedir. Postkoital kanama şikayeti olan hastalara önce jinekolojik muayene yapıldı, aktif kanama şikayeti olmayan hastalardan pap smear alındı, transvajinal ultrason ile uterin kavite değerlendirildi. Endometrial kalınlık, over kisti, polip, myom gibi jinekolojik patoloji olup olmadığı araştırıldı, sonrasında kolposkopi yapıldı. \%3,5 lik asetik asit ile serviks silindi kolposkopik muayene yapıldı ve şüpheli alanlardan biyopsi alındı. Transformasyon zonu net görülemeyen veya anormal sitoloji tespit edilen hastalara servikal biyopsi ve endoservikal biyopsi birlikte yapıldı. Ayrıca hipermenore ya da menometroraji şikâyeti olan ya da yapılan ultrasonografisinde endometriyal kalınlık olduğu düşünülen hastalara full probe küretaj uygulandı. Sitoloji sonuçları normal ve anormal (ASCUS, ASC-H, LGSIL, HGSIL ve invaziv kanser) olarak belirlendi. Kolposkopi sırasında alınan biyopsi ve endo-servikal biyopsi sonuçları normal ya da anormal (CIN 1, CIN 2, CIN 3 ve invaziv karsinoma) olarak gruplandırıldı.

Hastalar sitoloji sonuçlarına göre 2 gruba ayrıldı. 1. grup hastalar Pap Smear sonucu normal olarak gelenler, 2 grup hastalar pap smear testi anormal olarak gelen hastalardan oluşturuldu. Bu hastaların yaş ve menopoz durumları da kayıtlardan not edildi.

İstatistiksel analiz Statistical Package for the Social Sciences (SPSS) for Windows 15.0 software ile yapıldı. İstatistiksel analizde devamlı veriler için One-Way ANOVA Test’i ve kategorisel veriler için Ki-Kare Test’i kullanıldı. Papsmear için preinvaziv ve invaziv patoloji açısından sensitivite ve spesifisite hesaplandı. p <0,05 istatistiksel olarak anlamlı olarak kabul edildi. 


\section{Bulgular}

Bu çalışmaya postkoital kanama şikâyeti ile müracaat eden ve Pap Smear + Kolposkopi ve biyopsi yapılan 178 hasta dâhil edildi.

Grup 1: 122 hasta (PAP Smear: Negatif ) ve Grup 2: 56 (PAP Smear: Pozitif) hastadan

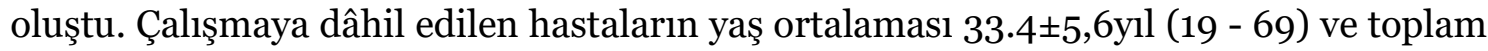
178 hastanın 36’sı (\% 20,22) menopozda idi. Grup 1 de 122 hastanın 10’u (\% 27,77) ve Grup 2 de ise 56 hastanın 26'sı menopozda (\%72,2), toplam 178 hastadan 142'si premenopoz döneminde $(\% 79,77)$ idi. Premenopoz açısından karşılaştırıldığında Grup 1 de premenopoz dönemindeki hasta sayısı 112 (\% 78,87) ve Grup 2 de 30 (\% 21,12) idi.

Tablo 1'de Grup 1 ve Grup 2'yi premenopoz ve menopoz yaş grubuna göre kolposkopi altında yapılan biyopsilerin patoloji sonuçlarına göre CIN 1, CIN 2-3 ve İnvaziv Karsinoma (Ca) açısından karşılaştırma yapıldığında bu oran anormal sitolojiye sahip (Grup 2) hastalarda daha yüksek oranda olduğu ve iki grup arasındaki farkın istatistiksel olarak anlamlı olduğu görülmektedir. Premenopoz döneminde CIN 1 (\%7,14; \%20), CIN 2-3 (\% 0,89; \%10), İnvaziv Ca (\% o; \%3,33) olarak saptandı (p<0,001). Menopoz hasta grubunda da sirasiyla CIN 1 (\% 0; \%11,53), CIN 2-3 (\% o; \%3,84), İnvaziv Ca (\% 0; \%3,84) $\mathrm{p}<\mathrm{O}, \mathrm{O01})$.

Tablo 1: Gruplar arasında patoloji sonuçlarının karşılaştırılması

\begin{tabular}{|c|c|c|c|c|c|}
\hline Biyopsi & $\begin{array}{c}\text { Grup 1 } \\
\text { (PAP Smear Negatif) }\end{array}$ & $\%$ & $\begin{array}{c}\text { Grup 2 } \\
\text { (PAP Smear Pozitif) }\end{array}$ & $\%$ & $\mathbf{p}$ \\
\hline Premenopoz $(n=142)$ & 112 & 78,87 & 30 & 21,12 & \\
\hline CIN 1 & 8 & 7,14 & 6 & 20 & \\
\hline CIN 2-3 & 1 & 0,89 & 3 & 10 & $<0,001$ \\
\hline İnvaziv Ca & - & - & 1 & 3,33 & \\
\hline Menopoz $(n=36)$ & 10 & 27,77 & 26 & 72,22 & \\
\hline CIN 1 & - & - & 3 & 11,53 & \\
\hline CIN 2,3 & - & - & 1 & 3,84 & $<0,001$ \\
\hline İnvaziv Ca & - & - & 1 & 3,84 & \\
\hline Toplam $(n=178)$ & 122 & 68,53 & 56 & 31,46 & \\
\hline
\end{tabular}

Gruplar arası karşılaştırmada Ki-Kare Testi kullanılmıştır. 
Tablo 2'de Preinvaziv ve İnvaziv patolojilerin ikili karşılaştırma sonuçları görülmektedir. $\mathrm{Bu}$ tablo incelendiğinde Preinvaziv kanserler açısından sadece Grup 1-2 (\%7,37 ve \%23,21) (p<0,001); invaziv kanser açısından ise Grup 1-2 (\%o ve \% 3,57) ( p<0,001) iki grup arasında istatistiksel olarak anlamlı fark olduğu görülmektedir (Tablo 2).

Tablo 2: Gruplar arasında Preinvaziv ve İnvaziv patolojilerin karşılaştırılması

\begin{tabular}{|l|c|c|c|}
\hline Patoloji Sonuçları & Grup 1 (n=122) & Grup 2 (n=56 ) & p \\
\hline Pre invaziv & $9(\% 7,37)$ & $13(\% 23,21)$ & $\mathrm{p}<0,001$ \\
\hline İnvaziv & - & $2(\% 3,57)$ & $\mathrm{p}<0,001$ \\
\hline
\end{tabular}

Gruplar arası karşılaştırmada Ki-Kare Testi kullanılmıştır.

Tablo 3'te pap smear testinin preinvaziv/invaziv patolojileri belirlemede sensitivite, spesifisite, pozitif prediktif değer, negatif prediktif değer ve olasılık oranı değerleri görülmektedir.

Tablo 3: Pap-smear'ın preinvaziv/invaziv servikal patolojileri bulmada sensitivite ve spesifisitesi

\begin{tabular}{|c|c|c|}
\hline Sitoloji & Hastalık (+) & Hastalık (-) \\
\hline Pozitif $(n=56)$ & $15(\% 26,78)$ & $41(\% 73,22)$ \\
\hline Negatif $(n=122)$ & $9(\% 7,37)$ & $113(\% 92,62)$ \\
\hline Değişken & Değer & 95\% Güven aralığg \\
\hline Sensitivite & 0,3820 & $0,3059-0,7318$ \\
\hline Spesifisite & 0,3849 & $0,3116-0,6723$ \\
\hline Pozitif prediktif değer & 0,4800 & $0,2843-0,6867$ \\
\hline Negatif prediktif değer & 0,9562 & $0,9130-0,9890$ \\
\hline
\end{tabular}

Sitolojisi pozitif olan 56 hastanın 15'inde (\% 26,78) hastalık görülürken 41'inde (\% 73,22) hastalık saptanmadı. Sitolojisi negatif olan 9 hastada (\% 7,37) hastalık pozitif iken 113 hastada (\% 92,62) hastalık negatif bulunmuştur. 
Sitolojinin sensitivitesi 0,3820, spesifitesi o,3849, pozitif prediktif değer 0,480o, negatif değer 0,9562 olarak saptanmıştır (Tablo 3).

\section{Tartışma}

Çalışmada postkoital kanama tanımı hastanın ilişki sonrası kanama ifadesi olarak kaydedilmiş ve bu kayıt üzerinden retrospektif olarak veriler toplanmıştır. Postkoital kanamanın en önemli nedeni servikal kanserdir. Serviks kanseri olan kadınların yaklaşık \%11'i (\%o,7-39) postkoital kanama ile ortaya çıkmaktadır ${ }^{1}$.

Kolposkopi yapılan vakalarda endoservikal kanser ihtimali olabileceği akılda tutulmalı ve belki de tüm vakalara kolposkopiye ek olarak endoservikal küretaj yapılması düşünülmelidir². Günümüzde halen postkoital kanama şikâyeti ile gelen hastalarda standart bir yönetim yaklaşımı söz konusu değildir³ . Genel olarak tekrarlayan veya inatçı postkoital kanaması olan veya spesifik anormal sitolojisi olan kadınlarda kolposkopi önerilmektedir ${ }^{4}$. Gözle görülür bir lezyonu olmayan ve smear tarama testi normal olan hastalarda ise kolposkopi yapılması tartışmalıdır. Ek olarak kolposkopi tekniği ve sınırları da tartışmalıdır5.

Gelişmiş ülkelerde en yaygın görülen jinekolojik malignite endometrium kanseridir. Postmenopozal kadınlardaki vajinal kanama öncelikle atrofiye sekonder oluşmaktadır. Fakat endometrium kanseri olan kadınların \%9o'ında başvuru şikâyeti vajinal kanamadır6. Adenokarsinom vakalarında skuamöz kanser vakalarına göre, postkoital kanama olma olasılığı daha düşüktür. Çünkü lezyon endoservikal kanalda ve yüksekte olmakta ve koitus sırasında travmadan korunabilmektedir ${ }^{7}$. Çalışmadaki hasta sayısı bu çalışmaya benzer olup hastaların \%3,47'sinde serviks kanseri; biri postmenopozal diğeri premenopozal dönemde olan 2 hastada $(\% 0,6)$ ise endometrium kanseri tespit edilmiştir. Gelişmiş ülkelerde 2012 yılı serviks kanseri insidansı \%o,99 iken endometrium kanseri insidansı \%1,47 olarak belirtilmektedir ${ }^{8}$.

Torre LA ve ark. kolposkopi sonrası servikal kanser tanısı konan 10 kadından 2'sinde işlem öncesi servikal bir lezyon olmadığını ve smear sonuçlarının normal geldiğini raporlamıştır ${ }^{9}$. Çalışmada negatif smear sonucu olan grupta invaziv servikal kanser bulunmamaktadır. Ayrıca kolposkopi yapılmasını hastaya bırakılmalıdır. Kolposkopi yapılsın ya da yapılmasın hastaların çoğunda postkoital kanama için bir neden bulunamayacaktır. 


\section{Sonuç}

Aşırı kanamayı açıklayacak herhangi bir neden bulunamayan hastalarda eğer kanama devam ederse ve özellikle hasta 35 yaşın üstünde ise endometriyal kavite de değerlendirilerek gerekirse endometriyal örnekleme yapılmalıdır. Çalışma sonuçları incelendiğinde postkoital kanamalı hastalarda konvansiyonel pap-smearın servikal preinvaziv/invaziv lezyonları tanımada sensitivitesi ve spesivitesinin düşük olduğu görülmektedir.

Sonuç olarak postkoital kanama şikâyeti olan hastalarda vajinal muayenede gözle görünür bir lezyon yoksa ya da smear sonucu negatif ise hastaya kolposkopi yapma zorunluluğu yoktur. Ancak muayene sırasında da kanaması olduğu görülen veya anormal smear sonucu olan hastalarda mutlaka kolposkopik muayene ve biyopsi yapılması gerekir. Ancak yine de bu konuda geniş vaka sayısına sahip randomize kontrollü çalışmalara ihtiyaç vardır.

\section{KAYNAKLAR}

1. Shapley M, Jordan J, Croft PR. A systematic review of postcoital bleeding and risk of cervical cancer. Br J Gen Pract. 2006;56(527):453- 60.

2. Tarney CM, Han J. Postcoital bleeding: a review on etiology, diagnosis, and management. Obstetrics and gynecology international. 2014;27(122):78-79.

3. Tehranian A, Rezaii N, Mohit M, Eslami B, Arab M, Asgari Z. Evaluation of women presenting with postcoital bleeding by cytology and colposcopy. Int $J$ Gynaecol Obstet. 2009;105:18-20.

4. Selo-Ojeme DO, Dayoub N, Patel A, Metha M. A clinico-pathological study of postcoital bleeding. Arch Gynecol Obstet. 2004;270:34-6.

5. Luesley D, Leeson S. Colposcopy and programme management. Guidelines for the NHS cervical screening programme. NHSCSP Publication. 2004;20:28-32.

6. Goldstein RB, Bree LR, Benson CB, et al. Evaluation of the woman with postmenopausal bleeding: society of radiologists in ultrasound-sponsored consensus conference statement. Journal of Ultrasound in Medicine. 2001;(10):1025-1036. 
7. Viikki M, Pukkala E, Hakama M. Bleeding symptoms and subsequent risk of gynecological and other cancers. Acta Obstet Gynecol Scand. 1998;77(5):564-9.

8. Pretorius R, Semrad N, Watring W, Fotheringham N. Presentation of cervical cancer. Gynecol Oncol. 1991;42(1):48-53.

9. Torre LA, Bray F, Siegel RL, Ferlay J, Lortet-Tieulent J, Jemal A. Global cancer statistics, 2012. CA: A Cancer Journal For Clinicians, 2015;65(2):87-108. 